\title{
Understanding immersion in 2D platform-based online collaborative learning environments
}

\author{
Gibran Alejandro Garcia Mendoza \\ Toyo University, Japan \\ Insung Jung \\ International Christian University, Japan
}

\begin{abstract}
Previous studies have revealed that when video gamers, or users of three-dimensional (3D) virtual worlds, display intense concentration coupled with an emotional engagement in their undertaking, they are affected by multisensory stimuli. This can lead to developing a feeling of detachment from the physical world, which, in turn, can lead to high levels of participation and engagement. Notwithstanding these results, it remains unclear as to whether students can experience the same kind of immersion in two-dimensional (2D) platform-based online collaborative learning spaces as has been achieved in video games and 3D worlds and, if they actually can, which features would lead to similar levels of increased engagement. This study is one of the first attempts to investigate the immersion experiences of students engaged in two 2D online collaborative learning platforms, one text-based and the other video-based. Data from eight students revealed that key features of immersion observed in video games and $3 \mathrm{D}$ worlds also appeared during the online collaborative activities but that the way such immersion was perceived by the students was greatly affected by the characteristics of the individual platform. When emotional engagement was considered, empathy was found to play an important role in the participants' immersion experiences.
\end{abstract}

\section{Implications for practice or policy:}

- Text-based platforms could be effective in motivating students to focus more on the postings, while video-based platforms may be more effective in generating empathy with others through observation of body language.

- When selecting a communication platform for online collaboration, sensory stimuli of the platform should be carefully examined.

- Empathy could be developed prior to an online collaborative activity so that students reflect on their thoughts and consider others' feelings for a more immersive learning experience.

Keywords: cognitive engagement, empathy, immersion, online collaboration, transportation, qualitative

\section{Introduction}

Previous studies of online collaboration (e.g., Guan et al., 2006; Perkins \& Murphy, 2006) proposed that variables like social presence and sociability are key factors in increasing participation and interaction among users in synchronous and asynchronous discussions both in required as well as in voluntary online collaborative works.

Social presence, which is defined as "the degree to which a person is perceived as a 'real person' in mediated communication" (Gunawardena, 1995, p. 151), is known to be a key element within interactions in online learning. It has a positive effect on students' motivation to participate and collaborate with others, and on overall satisfaction with instructors and courses (Richardson et al., 2017), and enhances students' cognitive engagement in the online discussion and collaboration process (Bai, 2003; Ngoyi \& Malapile, 2018).

Sociability is another variable that has been found to influence the cognitive engagement of students in online collaborative discussions. Kreijns et al. (2004) referred to sociability as "the extent to which a computer-supported collaborative learning environment is perceived to be able to facilitate the emergence of a sound social space with attributes such as trust and belonging, a strong sense of community, and good 
working relationships" (p. 157). Cognitive engagement, therefore, occurs in a social environment where trust, a sense of community and strong interpersonal relationships exist.

While previous studies into online collaborative discussions have mainly considered social variables such as social presence and sociability, they have continually ignored immersion; a psychological variable strongly related to attention, focus, and willingness to concentrate. Jerome and Witmer (2004) referred to immersion as "a feeling of being there in the artificial environment and to become removed from real-world stimuli" (p. 2613). Similarly, Witmer and Singer (1998) defined immersion as "a psychological state characterised by perceiving oneself to be enveloped by, included in and interacting with an environment that provides a continuous stream of stimuli and experiences" (p. 227). They claimed that when individuals feel fully immersed, they feel as if they are able to directly interact with the virtual environment. This immersion sensation is, therefore, believed to be a result of how well users respond psychologically within a virtual environment stimulus (immersive response) rather than on the novelty and multisensory capabilities of the technology in use (system immersion).

Several studies have claimed that online spaces generating high levels of immersion produce high levels of social presence (e.g., Bowman \& McMaham, 2007; Witmer \& Singer, 1998) and are positively related to the users' perceived usability and hedonic motivation (Shin, 2019), which is likely to result in high levels of participation and engagement. However, a certain degree of care must be applied to such claims as they arise mainly from studies on video games and 3D worlds with high levels of virtuality. Immersion has hardly been explored in online learning platforms such as Piazza, Moodle and Google Hangouts, with low levels of virtuality that are commonly used in formal educational settings.

Immersive virtual environments can shift students' frame of reference from being exocentric, a view of a phenomenon from the outside, to egocentric, a view from within the phenomenon, which can lead to a more embodied and concrete learning experience (Dede, 2009) together with higher achievement and learning motivation in certain subject areas (Shi et al., 2019). Zhou and Deng (2009) believed that this happens because when people become a part of the world constructed in their minds, the imaginary world becomes a virtual reality. This, they argued, can enhance students' confidence in their academic abilities by facilitating the transfer of knowledge to the real world via simulated situations. As collaborative learning via online discussion forums has become more widespread in formal educational settings, students' subjective experience of immersion cannot be ignored as it is strongly related to attention, focus and willingness to concentrate - key elements required for cognitive engagement.

\section{Key features of immersion}

The following key features of immersion have been identified in studies conducted in video games and 3D worlds. It is entirely possible that these features of immersion could aid in the understanding of immersion in $2 \mathrm{D}$ platform-based online collaborative learning.

Firstly, immersion requires attention. Nakamura and Csikszentmihalyi (2014) stated that intense focus and concentration in what one is doing in the present moment is one of the main prerequisites to entering a subjective space. Brown and Cairns (2004), in a study conducted with video game players, identified three sources of attention: visual, auditory and mental. They noted that the level of immersion felt by gamers correlates to the number of attentional sources experienced and the degree to which each is experienced. Not surprisingly, more effort is required to play the video game when players are required to pay attention to sight and sound simultaneously.

Secondly, immersion involves emotional engagement. This can include a feeling of being challenged, a state of anxiety or feelings of enjoyment and empathy. Nakamura and Csikszentmihalyi (2014) stated that the feeling of being challenged is crucial to having an immersive experience; it is also important for individuals to tackle a series of manageable goals, making any activity extrinsically rewarding. This was observed by Jennett et al. (2008) in an experiment where video gamers who became caught up in challenging tasks also became highly engaged emotionally. Those who developed some proficiency in the game felt more pressure to win the game and, thus, became highly anxious. These findings caused Jennett's team to conclude that becoming emotionally charged is key in video game immersion. In an interview with seven gamers, Brown and Cairns (2004) also found that those who lacked empathy with their character did not feel immersed in the game. 
Thirdly, multisensory stimulation is important if one is to be immersed in an activity. Slater et al. (1996) claimed that the reason extensive displays tend to be considered immersive is because they accommodate multiple sensory systems and because information is received by these systems from multiple directions at the same time. According to Höll et al. (2003), most users rely exclusively on auditory and visual sensations, and so limit the obtaining of additional information from virtual environments. Bowman and McMahan (2007) opined that it is important to design systems efficient at stimulating different senses. The more senses a system stimulates, the more it enables individuals to construct their own internal mental models of reality; the higher the levels of sensory fidelity a virtual space provides, the more similar to those real-world senses they become. Yao and Kim (2019) revealed that interactive virtual reality exercising games with multisensory stimulation led to a higher level of presence, psychological arousal and physical exercising performance.

Finally, it must be noted that the combination of attention, emotional engagement and multisensory stimulation may lead to individuals who remain focused and who continue to work on a specific task, leading to a feeling of physical world detachment. At this point, the individual feels cut off from reality to the extent that the activity undertaken is all that matters. Jennett et al. (2008) believed that total immersion could be the precursor for "flow" which, according to Csikszentmihalyi (1990), provides individuals with a sense of discovery and a creative feeling of transporting themselves into a new reality.

Although these features provide a better understanding of immersion, they tend to be limited to explaining users' experiences with video games and 3D virtual worlds, which leaves more traditional 2D online platforms commonly used for academic tasks barely explored. Witmer and Singer (1998) stated that immersion relies on how well individuals connect within the online environment stimulus rather than in the novelty of the technology in use. This opens up the possibility that $2 \mathrm{D}$ online platforms could, therefore, enable students to become immersed in the activity undertaken providing them with a perception of existence within the online environment. This could be advantageous in carrying out academic tasks that require high levels of cognitive engagement. Nevertheless, it remains unclear whether students truly experience immersion in 2D platform-based online collaborative learning spaces to the same extent they do in video games and 3D virtual worlds. Moreover, it is not clear which features of immersion, if any, lead students to feel immersed in such 2D online platforms and if these features differ from those of 3D virtual worlds.

To discover more about immersion in a 2D online platform used for group discussion and collaboration, this exploratory study investigated the observable features of immersion in online collaborative learning which utilised both text- and video-based 2D platforms. At the outset, it was expected that features of immersion observed in the text-based platform would be different from those appearing in that of the videobased platform as the two platforms stimulate different senses. A qualitative approach was adopted in examining the immersion experiences of eight fully online students.

\section{Methods}

\section{Sample and procedure}

The study was conducted within an online course from a national open university based in the Philippines. An open university was selected for the study because existing students were already in the habit of using online platforms for collaborative discussion activities, making it possible for researchers to readily investigate immersion. The online course lasted 10 weeks and aimed at teaching introductory programming and computer science knowledge to fully online students.

Two activities were designed for use in the study. The first was a text-based collaborative activity which the course instructor called Recitation 1, and the second was a video-based collaborative activity called Recitation 2. In order to carry out these two activities, the 43 enrolled students were randomly assigned to 8 groups of 5 or 6 students by the course instructor. Each team was required to work on both types of activities. 
- In the text-based Recitation 1 activity, the groups were required to collaboratively answer three semi-structured questions based on course readings for two weeks from the 6th to the 19th of February 2017. Students first had to share and discuss their individual answers and opinions before collaboratively formulating a group wrap-up report. Piazza, a text-based asynchronous online platform, was used as the collaborative discussion space.

- In the video-based Recitation 2 activity, students were required to hold a synchronous video-based group activity by creating a YouTube live event between the 20th and 25th of February 2017. Each group was required to discuss four semi-structured questions based on course readings within a time frame of 30 minutes. After the discussion, each group was tasked with compiling a collaborative wrap-up report.

Prior to the start of data collection, we obtained approvals from the Research Ethics Committee of the second author's institution (\#2016-26) and the Research and Publication Committee of the open university in the Philippines.

Of the 43 students enrolled in the online course, eight students ( 5 males and 3 females) voluntarily agreed to participate in the study. The eight participants ranged in age from 18 to 50 years old. Seven were of Filipino nationality; the other, a male student, who had been residing in the Philippines for several years, was from a Middle Eastern country. All the participants were enrolled in the same course at the time of the interviews.

Table 1 shows a description of the eight participants. Pseudonyms were created for ethical and privacy reasons using a number preceded by the code "MS" for male and "FS" for female.

Table 1

Participants' age, gender and student status

\begin{tabular}{llll}
\hline Response ID & Age & Gender & Status \\
\hline FS1 & $18-20$ & F & Full-time local student \\
FS2 & $21-30$ & F & Part-time (working) local student \\
FS3 & $21-30$ & F & Part-time (working) local student \\
MS1 & $41-50$ & M & Part-time (working) local student \\
MS2 & $21-30$ & M & Part-time (working) local student \\
MS3 & $21-30$ & M & Full-time local student \\
MS4 & $21-30$ & M & Part-time (working) local student \\
MS5 & $21-30$ & M & Full-time local student \\
\hline
\end{tabular}

\section{Instruments}

An evaluation rubric for a group wrap-up report

We developed a rubric to evaluate each group's wrap-up report. This rubric contained criteria to evaluate organisation in writing, content quality, grammar and spelling, interest level and timeline. It also asked each evaluator's opinion on the students' understanding of the topic, their critical thinking and the uniqueness of their contribution.

\section{Questionnaire for in-depth interviews}

Initially, we developed a questionnaire with 31 items to explore the participants' perception of immersion when discussing and collaborating with their group mates. The questions posed were designed based on a review of the literature of immersion and related areas, which was discussed above, such as sociability and social presence in online spaces, cognitive absorption and flow (Brown \& Cairns, 2004; Gao et al., 2010; Gunawardena, 1995; Jennett et al., 2008; Nakamura \& Csikszentmihalyi, 2014). To make sure that the questions were addressing the concepts in question, we shared the questionnaire with the professor in charge of the online course in the present study and two external collaborators from different universities. Based on their feedback, we developed a refined version of the questionnaire to be used in the present study. The final draft consisted of a total 23 of open-ended questions grouped under four categories: attention, emotional engagement, multisensory environment and physical world detachment. 


\section{Data collection and analysis}

\section{Group wrap-up reports}

After copy-pasting the files in Microsoft Word, we first analysed each group report regarding the contextual spelling, grammar, punctuation, sentence style and vocabulary using Grammarly, a well-known online grammar checker software. We then evaluated the quality of each report based on the rubric explained in the Instruments section.

\section{In-depth interviews}

The interviews were semi-structured and were conducted individually via Skype, a VoIP system, as the participants were located in various areas across the Philippines. Each interview lasted around 30 minutes and was recorded with the participants' permission. This was the first time that any of the eight participants had shared these experiences, and therefore particular care was taken to phrase questions in such a way that words were not put into the interviewee's mouth or in any way influence their responses.

Each interview was transcribed and then each transcript was compared to the interview recording twice in order to ensure that there was no missing information. The interview transcripts were then sent to the interviewees via email for further revisions, clarifications and possible corrections.

The final versions of the transcribed data were analysed using the content analysis method. Qualitative analysis software (QDA Miner 5) was used to code the transcriptions of each interview. The codes were then sorted into the four clusters of immersion: attention, emotional engagement, multisensory environment and physical world detachment.

\section{Validity}

We used triangulation to increase the validity of research results. First, we collected data from group wrapup reports and in-depth interviews with learners and drew inferences from previously published research in similar settings and discussions with three experts in the fields of education, psychology and educational technology. Subsequently, we evaluated the quality of the wrap-up reports with the help of two external collaborators. We evaluated the group-wrap-up reports separately before getting together with the two external collaborators to compare our results and share our comments and feedback. For the interview analysis, we adopted a member check and obtained confirmation from the participants. The application of triangulation of data proved advantageous in fair and diverse analysis and interpretation of the data.

\section{Findings}

The interview data for both online learning platforms used in the study revealed the existence of three features of immersion: attention, emotional engagement and physical world detachment. However, it should be noted that the degree to which immersion took place varied and was experienced differently in each platform.

\section{Attention}

When asked to what extent the recitations held their attention, all eight participants responded that in both text- and video-based collaborative activities the topics of discussion were of sufficient interest to hold their attention. Overall, the discussion topics, particularly that regarding online privacy in Recitation 2 , were considered to be important and relevant in their study area, especially so by those participants who thought of themselves as being "tech-savvy." It was the importance of the discussion topics and their relevance to both personal and professional lives that held the attention of the participants.

Interestingly, although the discussion topics held the interest of the participants, it was the type of online platform that influenced the focus and the degree of their attention. In the text-based Recitation 1 activity, five participants reported focusing more on understanding "the subject matter" of the messages than they did on the individual who posted the messages and were, therefore, able to think deeply about the messages and create a mental representation of the situation described. In the video-based Recitation 2 activity, which closely resembled physical face-to-face interactions, the participants tried to understand how their group mates felt about the discussion by paying attention to the intonation of voices and accompanying facial 
expressions, especially after a period of "dead air" in the discussions. FS1 and FS2 reported that trying to understand their group mates' feelings was distracting because their minds wandered while listening to them.

\section{Emotional engagement}

When asked about the degree to which they felt emotionally engaged during the online collaborative activities, the participants gave differing responses for each recitation. For Recitation 1, five of the participants explicitly stated that they felt no emotional attachment to their group mates. The absence of social presence and the formality of the written language were two factors that prevented them from developing any feelings. Nevertheless, they reported feeling emotionally engaged with the discussion topics; some of the participants felt overwhelmed, while others felt challenged and motivated. FS1, for instance, admitted to being overwhelmed by the questions and feeling anxious about not knowing a great deal about the topics under discussion. These emotions made him realise that he needed to watch videos on YouTube about the topics in order to gain a better understanding for future group discussion. Conversely, MS1 felt very confident in discussing the topics because he had previously taken courses in related fields. FS3 felt very motivated after realising "how smartly" her group mates answered the questions. This encouraged her to push herself to come up with "better answers" because she did not want to post anything "below average." Conversely, MS2 reported not feeling challenged at all but feeling "very engaged with the topics" because he considered himself a "tech-savvy person."

As for Recitation 2, the participants reported experiencing different feelings at various stages during the discussion. Prior to the video-based discussion, all interviewees admitted to feeling anxious, awkward, reluctant and shy in meeting their group mates on screen. At the beginning of the collaborative activity, feelings of discomfort were expressed, which were blamed on technical problems. MS1 mentioned that due to some technical issues he felt he could not interact with his group mates. In the same way, MS2 felt uneasy because of the unstable set-up of his Internet connection, and FS3 commented on feeling uncomfortable when she could hardly see a group mate's face because of poor room lighting. However, after overcoming these difficulties, most interviewees reported becoming more comfortable within their group. After seeing each other via Google Hangouts, they began building friendships and they felt motivated by the way their group mates helped each other and tried their best during the activity. It was during Recitation 2 when they experienced "the teamwork" as they realised that their opinions were heard in real time, engendering feelings of deeper engagement. They also felt as if "the team" was "moving towards" and "building" a common goal while becoming much closer after working together through both recitations.

\section{Physical world detachment}

The interviewees were asked whether they had been focused to a point where they had the feeling of being transported to a different place or detached from the physical world. In the text-based Recitation 1, five interviewees reported no feelings of being transported to a different place. MS1 and MS2, for example, did not feel any sensations of being transported because it was clear to them that they were dealing solely with text. MS4, on the other hand, had no feelings of being transported unless he kept thinking deeply about the topic under discussion. Similarly, FS3 did not feel transported but was able to focus because Piazza was an online space that put her mind to work.

Nevertheless, the three remaining students reported experiencing sensations of being detached from the physical world. FS1 recalled that at times she did not notice what was happening around her, but this happened only when her brain was focused on her emotions and on what she was going to say while composing her text messages. Similar experiences were reported by MS5 and MS3. For MS5, it felt as if he were transported to another dimension while holding text-based discussions with his group mates. From time to time, he felt as if his body was in one place but his "mind and heart" were in another place. He claimed that he actually tried to put himself in his counterparts" shoes and imagined himself "being by their sides" so that the conversation could proceed smoothly. He added that although he had a physical disability, he wanted to show he was "as capable" and "normal" as any other student in his group. Alternatively, MS3's feeling of detachment occurred only when he "got engaged in deep conversations" that both he and his counterpart enjoyed causing them to exchange text-messages "every second". He remembered staring at his phone without noticing what was happening around him in the real-world environment. 
In the video-based Recitation 2 activity, four of the interviewees recalled experiencing a feeling of being transported to a different place while interacting with their group mates. FS1 remembered having "a series of experiences" when discussing and explaining her ideas to the extent that she did not notice the environment around her. MS1 and MS5 also felt as if they were "physically separated [from the real world]" and "entering the virtual world" while holding video-based discussions. According to MS1, "It was a feeling of having no barriers between the online and physical set-ups." FS2 shared similar experiences, but she pointed out that in order to feel this way it was necessary for her to see "the background" (the place where her counterparts were located) through her video camera. Conversely, MS2 did not feel any detachment from the physical world. For him, it was "more like peeping through a different window," but he was still aware of "being physically present in his room."

Interestingly, there was a common personal trait among these participants in that they all felt socially responsible for helping others. As MS3 stated, "I felt responsible for acquiring new knowledge not only for myself but also for the support of others." In the same vein, MS5 commented, "when my classmates are having a hard time understanding a topic, I [help them out] but without showing them the answer". FS2 also said that many people were willing to help out or explain something she did not understand; however, she felt bad when she could not make any contribution or when she did not know how to explain something clearly to others.

\section{Quality of group wrap-up reports}

Overall, the results of the analysis of the wrap-up reports revealed that in both recitations, the quality of reports was heavily influenced by the degree of interactions among group members, which either enhanced or hindered the exchange of ideas and construction of new knowledge in the collaboration.

In both recitations, the groups whose members had little interaction showed a lack of flow between ideas in each paragraph and a lack of smooth transitions between sentences or when expressing opposite arguments or ideas. We also observed that some of the reports had sentences that were out of place, and some paragraphs included large and unedited comments previously made by a single group member during the discussion period. As a result, these groups produced overly long wrap-up reports, whether they were in Recitation 1 or Recitation 2.

Critically, the groups whose members interacted more actively showed a synthesis of their members' ideas. Interestingly, few grammar or punctuation mistakes were found in their reports. Overall, their points were logically ordered with a sharp sense of beginning and end. However, they fell short of providing more specific examples to illustrate some ideas, and vocabulary was a bit stiff and unimaginative.

In addition to the degree of interaction, there were other factors influencing the quality of the wrap-up reports in both recitations: the interventions of the key group members who gathered, organised, combined and edited the group members' ideas, and those who took the lead in managing and engaging all other group members in the editing process of the reports. Finally, the degree of argumentation in all discussions was definitely another factor affecting the quality of the wrap-up reports.

\section{Discussion}

The content analysis of the interview responses indicates that most participants had two different, yet closely related immersive experiences: in the text-based Recitation 1 activity, this was described as a feeling of being detached from the physical world, while in the video-based Recitation 2 activity, it was of a feeling of being transported to another place.

In the text-based Recitation 1 activity, five participants focused more on the content of the messages than on the person who posted them or on their surroundings. Through this, they could better understand the messages and their meaning. Although five students did not reach a higher level of immersion, of total detachment from the physical world, three students reported having a series of world detachment experiences throughout Recitation 1. Perhaps those students (FS1, MS3, and MS5) exchanged personal messages synchronously with others using another messaging platform. During these interactions, they might have attempted to convey their emotions through their messages and made a conscious effort to put 
themselves in their group mates' place so that conversation flowed more smoothly. These participants invested more time and effort in thoroughly understanding their group mates' messages. This finding is consistent with Brown and Cairns' (2004) argument that the more investment students make in an activity, the more they become immersed in it. Moreover, it supports the finding by An et al. (2020), who explored, quantitatively, the way individuals' respond to narratives posted on an online bulletin board in the context of social support solicitation. The results of their study indicated that the participants who identified more with the support seekers provided more emotional support than those who did not. Interestingly, they also found that "support soliciting narratives could induce a mental state in which the participants temporarily lose self-awareness and internalise the support seeker's perspective, goals and emotions" (An et al., 2020, p. 7).

Remarkably, the immersive experience in Recitation 1 resembles a phenomenon called narrative transportation, which refers to the experience of being consumed by the world of a story. According to Green and Fitzgerald (2017), this happens when “a person's mental systems and capacities become concentrated on events occurring in the story, causing individuals to lose track of time and lack awareness of their surrounding environment" (p. 2). In this psychological state, individuals may also feel strong emotions towards the characters of the story and experience different intensities of identification with the characters as a result of the narrative. This type of immersion in abstract reasoning about actions, events, or goals also resembles another phenomenon referred to as cognitive immersion, which is "the mental involvement in problem thinking and fantasy" (Norman, 2010, p. 2) and is closely related to emotions (Mullins \& Sabherwal, 2020). Up to now, however, this term has been limited to the field of games.

During the discussions following the video-based Recitation 2 activity, the feeling of being transported to another place was reported as being strongly perceived; four students felt as if they were sharing the same physical space with their group mates because they could see each other's locations, such as a room or an office through their cameras while conversing. The visual richness provided via video largely contributed to the participants' sensations of being transported. This finding matches those observed by Brown and Cairns (2004), who discovered that the level of immersion is correlated to the number of attentional sources and the degree of each attentional type. Compared with the text-based discussion, the video-based synchronous discussion setting requires more effort in order to pay attention to sight and sound simultaneously. This phenomenon resembles the concept Bowman and McMahan (2007) described as visual immersion, which is "how close the visual output is to real-world visual stimuli" (p. 38). Brown and Cairns (2004) explained that "this happens when an individual's cognitive and perceptual capacities are tricked into believing that they are somewhere other than their physical location" (p. 1297).

The findings in the video-based Recitation 2 are also consistent with those of Rooney and Hennessy (2013), who claimed that an increase in realism can sustain individuals' attention because the human visual system engages with perceptually realistic images similar to those perceived in everyday life. Rooney and Hennessy came up with this claim after exploring and comparing self-reported emotional arousal of two groups of individuals who watched 2D and 3D films. They found that individuals were less likely to be distracted when they watched 3D films in comparison to watching 2D films, suggesting that movies with higher levels of perceptual realism can hold an individual's attention for longer. Nevertheless, they also found that these two types of technologies had no significant influence on the emotional arousal of the individuals in either group. Taking these claims into consideration, we suggest albeit cautiously, that although the visual richness of the video-based recitation held participants' attention, leading them to a feeling of transportation, it was the emotional arousal created by the human-to-human interaction which played the more important role in the perception of immersion.

The feeling of being detached from the physical world experienced only by three students in the text-based Recitation 1 activity goes beyond transportation and requires extra effort. This feeling of world detachment was experienced only by those who thought deeply about the topic while recreating mental representations of the situation explicitly described in posted messages and, at the same time, attempting to empathise with their group mates whom they had yet to meet through the video-based Recitation 2 activity. Empathy made these students curious to learn more about the others and to build additional connections with them via synchronous messaging on Piazza. This helped to reduce communication barriers during conversations and made interactions more comfortable. 
Interestingly, a common trait among the participants who felt detached from the physical world in Recitation 1 and also by those who felt transported to another place in Recitation 2 was the effort made to understand their counterparts' feelings, the consideration of other individuals' perspectives and the attempt to understand the constructs inside others' minds. This last ability can be closely related to empathy, which, according to Alan Alda, "is knowing what their point of view is, what they are feeling, and what they are thinking" (Lanier, 2017). Empathy towards others may be closely related to the sense of social responsibility, described by some of the participants as understanding others' needs and concerns and requiring extra mental effort.

The findings of the present study mirror the previous findings of Brown and Cairns (2004) in that only those who truly empathised with the video game characters felt immersed in the online gaming environment. The findings further support the claims of Collins (2014) that individuals who scored high in a 28-item empathy scale were more likely to engage in individual conversations using Facebook's chat functions and that the amount of time spent online correlated positively with empathy. It appears that both Collins' quantitative study and the present qualitative study support the important role of empathy in experiencing immersion in online environments, by connecting humans to each other or to virtual characters emotionally and realistically.

\section{Conclusions and future work}

The purpose of this study was to examine the immersion experiences of eight fully online students who engaged in both text- and video-based 2D online collaborative learning platforms. The study, after investigating immersion in $2 \mathrm{D}$ online discussion platforms, where virtuality was low when compared to 3D virtual worlds, found that empathy was key to the perception of immersion in both text-based and videobased online collaborative discussions. In effect, a personal trait of empathising with others, which could be associated with the feeling of being socially responsible for helping others, was crucial in not only helping the participants to reflect on their own actions and thoughts but also in helping them to consider other perspectives and helping them to understand what happens inside others' minds.

The study also revealed that all three features of immersion observed in video games and 3D worlds attention, emotional engagement and physical world detachment - also appeared in the 2D online learning platforms. Immersive experiences, especially in the text-based discussions, were found to be the results of two processes: a cognitive process of deep thinking and the construction of mental representations or models in order to understand the topic or situation under discussion; and also a process of getting emotionally drawn by the task set or getting emotionally involved through empathy with others who share the same virtual space.

In conclusion, immersion in 2D learning platforms can be viewed as a process of becoming involved with a task in a virtual collaborative environment to the extent of becoming removed from real-world stimuli. This process, in which the type of online platform in use and participants' empathic behaviour play key roles, consists of three features: attention, emotional engagement and detachment from the physical world or transportation to another world.

The present study found that empathy, a personal trait, plays an important role in the immersion experiences of online learners. There may be other personal traits, such as anxiety and introversion that could hinder fully immersive experiences (Jurnet et al., 2005), or individual tendencies towards mental imagery production, daydreaming and emotional response that could promote full immersion (Green \& Fitzgerald, 2017), or even a personal tendency to imagine oneself in the place of others when one is more likely to feel transported into a filmed narrative while experiencing enjoyment (Hall \& Bracken, 2011). Future studies are needed to examine the characteristics of individuals who become highly immersed in online learning to discover which of their personal traits react with various online experiences.

\section{Limitations}

The study, it must be said, has a few limitations. Firstly, it was a small-scale project with only eight students; thus, careful understanding of the findings and future research with a larger sample size is needed. Secondly, the study measured self-reported perceptions of immersion in online collaborative learning 
settings, which may have rendered response bias. Future research measuring immersion quantitatively and objectively during the online collaborative activities is needed to complement the findings of the present study.

\section{References}

An, Z., Meng, J., \& Mendiola-Smith, L. (2020). The role of identification in soliciting social support in online community. Computers in Human Behavior, 104, 1-10. https://doi.org/10.1016/j.chb.2019.106181

Bai, H. (2003). Social presence and cognitive engagement in online learning environments. In A. Rossett (Ed.), Proceedings of E-Learn 2003: World Conference on E-Learning in Corporate, Government, Healthcare, and Higher Education (pp. 1483-1486). AACE. https://www.learntechlib.org/p/14492/

Bowman, D. A., \& McMahan, R. P. (2007). Virtual reality: How much immersion is enough? IEEE Computer, 40(7), 36-43. https://doi.org/10.1109/MC.2007.257

Brown, E., \& Cairns, P. (2004). A grounded investigation of game immersion. Extended Abstracts of the 2004 Conference on Human Factors and Computing Systems: CHI'04 (pp. 1297-1300). https://doi.org/10.1145/985921.986048

Collins, M. F. (2014). The relationship between social media and empathy [Master's thesis, Georgia Southern University]. https://digitalcommons.georgiasouthern.edu/etd/1150/

Csikszentmihalyi, M. (1990). Flow: The psychology of optimal experience. Harper Row. https://doi.org/10.5465/amr.1991.4279513

Dede, C. (2009). Immersive interfaces for engagement and learning. Science, 323, 66-69. https://doi.org/10.1126/science.1167311

Gao, Q., Dai, Y., Fan, Z., \& Kang, R. (2010). Understanding factors affecting perceived sociability of social software. Computers in Human Behavior, 26(6), 1846-1861. https://doi.org/10.1016/j.chb.2010.07.022

Green, M. C. \& Fitzgerald, K. (2017). Transportation theory applied to health and risk messaging. Oxford Research Encyclopedia, Communication (pp. 1-25). Oxford University Press. https://doi.org/10.1093/acrefore/9780190228613.013.261

Guan, Y.-H., Tsai, C.-C., \& Hwang, F.-K. (2006). Content analysis of online discussion on a senior-highschool discussion forum of a virtual physics laboratory. Instructional Science, 34(4), 279-311. https://doi.org/10.1007/s11251-005-3345-1

Gunawardena, C.N. (1995). Social presence theory and implications for interaction and collaborative learning in computer conferences. International Journal of Educational Telecommunications, 1(2), 147-166. https://www.learntechlib.org/primary/p/15156/

Hall, A. E., \& Bracken, C. C. (2011). "I really liked that movie": Testing the relationship between trait empathy, transportation, perceived realism, and movie enjoyment. Journal of Media Psychology: Theories, Methods, and Applications, 23(2), 90-99. https://doi.org/10.1027/1864-1105/a000036

Höll, D., Leplow B., Schönfeld R., \& Mehdorn M. (2003) Is it possible to learn and transfer spatial information from virtual to real worlds? In C. Freksa, W. Brauer, C. Habel, \& K. F. Wender (Eds.), Lecture Notes in Computer Science (Vol. 2685, pp. 143-156). Springer. https://doi.org/10.1007/3540-45004-1 9

Jennett, C., Cox, A. L., Cairns, P., Dhoparee, S., Epps, A., Tijs, T., \& Walton, A. (2008). Measuring and defining the experience of immersion in games. International Journal of Human-Computer Studies, 66(9), 641-661. https://doi.org/10.1016/j.ijhcs.2008.04.004

Jerome, C. J., \& Witmer, B. G. (2004). Human performance in virtual environments: Effects of presence, immersive tendency, and simulator sickness. Proceedings of the Human Factors and Ergonomics Society Annual Meeting, 48(23), 2613-2617. https://doi.org/10.1177/154193120404802302

Jurnet, I. A., Beciu, C. C., \& Maldonado, J. G. (2005). Individual differences in the sense of presence. In Proceedings of the 8th Annual International Workshop on Presence (pp. 133-142). The International Society for Presence Research. https://astro.temple.edu/ lombard/ISPR/Proceedings/2005/Jurnet,\%20Beciu,\%20Maldonado.pdf

Kreijns, K., Kirschner, P. A., Jochems, W., \& van Buuren, H. (2004). Determining sociability, social space, and social presence in (a)synchronous collaborative groups. Cyberpsychology \& Behavior, 7(2), 155-172. https://doi.org/10.1089/109493104323024429

Lanier, T. (Host). (2017, November 14). How to avoid communication breakdowns [Audio podcast]. The New Man. http://www.thenewmanpodcast.com/2017/11/alan-alda-if-i-understood-you/ 
Mullins, J. K. \& Sabherwal, R. (2020). Gamification: A cognitive-emotional view. Journal of Business Research, 106, 304-314. https://doi.org/10.1016/j.jbusres.2018.09.023

Nakamura, J., \& Csikszentmihalyi, M. (2014). The concept of flow. In M. Csikszentmihalyi (Ed.), Flow and the foundations of positive psychology: The collected works of Mihaly Csikszentmihalyi (pp. 239263). Springer. https://doi.org/10.1007/978-94-017-9088-8

Ngoyi, L., \& Malapile, L. S. (2018). Social presence and student engagement in online learning. In M. Khosrow-Pour (Ed.), Student engagement and participation: Concepts, methodologies, tools, and applications (pp. 1228-1237). IGI Global. https://doi.org/10.4018/978-1-5225-2584-4.ch061

Norman, K. L. (2010). Development of instruments to measure immerseability of individuals and immersiveness of video games (Human-Computer Interaction Technical Report 12-5-10). University of Maryland. http://www.cs.umd.edu/hcil/trs/2010-33/2010-33.pdf

Perkins, C., \& Murphy, E. (2006). Identifying and measuring individual engagement in critical thinking in online discussions: An exploratory case study. Journal of Educational Technology \& Society, 9(1), 298-307. http://www.jstor.org/stable/jeductechsoci.9.1.298

Richardson, J.C., Maeda, Y., Lv, J., \& Caskurlu, S. (2017). A meta-analysis of social presence in relation to students' satisfaction and learning. Computers and Human Behavior, 71, 402-417. https://doi.org/10.1016/j.chb.2017.02.001

Rooney, B., \& Hennessy, E. (2013). Actually in the cinema: A field study comparing real 3D and 2D movie patrons' attention, emotion, and film satisfaction. Media Psychology, 16(4), 441-460. https://doi.org/10.1080/15213269.2013.838905

Shi, A., Wang, Y., \& Ding, N. (2019): The effect of game-based immersive virtual reality learning environment on learning outcomes: Designing an intrinsic integrated educational game for pre-class learning. Interactive Learning Environments. https://doi.org/10.1080/10494820.2019.1681467

Shin, D. (2019). How does immersion work in augmented reality games? A user-centric view of immersion and engagement. Information, Communication \& Society, 22(9), 1212-1229. https://doi.org/10.1080/1369118X.2017.1411519

Slater, M., Linakis, V., Usoh, M., \& Kooper, R. (1996). Immersion, presence and performance in virtual environments. In Proceedings of the ACM Symposium on Virtual Reality Software and TechnologyVRST 1996 (pp. 163-172). ACM. https://doi.org/10.1145/3304181.3304216

Witmer, B. G., \& Singer, M. J. (1998). Measuring presence in virtual environments: A presence questionnaire. Presence, 7(3), 225-240. https://doi.org/10.1162/105474698565686

Yao, S. \& Kim, G. (2019). The effects of immersion in a virtual reality game: Presence and physical activity. In X. Fang (Ed.), Proceedings of HCII 2019: 21st HCI International Conference (pp. 234 242). Springer. https://doi.org/10.1007/978-3-030-22602-2_18

Zhou, N.-N., \& Deng, Y.-L. (2009). Virtual reality: A state-of-the-art survey. International Journal of Automation and Computing, 6(4), 319-325. https://doi.org/10.1007/s11633-009-0319-9

Corresponding author: Gibran Alejandro Garcia Mendoza, garcia@toyo.jp

Copyright: Articles published in the Australasian Journal of Educational Technology (AJET) are available under Creative Commons Attribution Non-Commercial No Derivatives Licence (CC BY-NC-ND 4.0). Authors retain copyright in their work and grant AJET right of first publication under CC BY-NC-ND 4.0 .

Please cite as: Garcia Mendoza, G. A., \& Jung, I. (2021). Understanding immersion in 2D platformbased online collaborative learning environments. Australasian Journal of Educational Technology, 37(1), 57-67. https://doi.org/10.14742/ajet.6106 